\title{
Study on the Epochal Implications of Chinese Jadeite Carving Technology Performance*
}

\author{
Xiaochen Geng \\ Xiamen Academy of Arts and Design, Fuzhou University \\ Xiamen, China \\ Postdoctoral Research Center \\ Nanjing Normal University \\ Nanjing, China
}

\author{
Shaopeng $\mathrm{Wu}$ \\ Xiamen Academy of Arts and Design, Fuzhou University \\ Xiamen, China
}

\begin{abstract}
This paper briefly describes the craft characteristics of traditional jadeite carving, compares and discusses the creative concept of jadeite carving. Through the indepth explanation of the folk crafts and expressions of the academic school, the author gradually develops and discusses the ideas and integration of academic school jadeite carving and folk jadeite carving, which is also of great significance to the inheritance and development of Chinese crafts technology and the protection of intangible cultural heritage.
\end{abstract}

Keywords-jadeite carving; folk craft; academic school; performance

\section{INTRODUCTION}

However, with the fission of the times, the traditional aesthetic concept is no longer applicable to people's interest to jadeite and aesthetic taste. As a category of traditional arts and crafts, Jadeite carving relies on the nourishment of traditional culture in the creation. Facing the context of the new culture, how to expand the artistic conception in creation consistent with the times without losing the culture it contains? In the innovation of jadeite carving, faced with the university's craft design works, most people have a very active attitude towards the works of academic school, and a conservative attitude towards the craftsmen because they lack of innovation awareness and innovation ability. Therefore, the design and creative concept of integrating folk crafts with that of academic school is the mainstream of the current era.

\section{THE CRAFT CHARACTERISTICS OF JADEITE CARVING}

The information age has continuously promoted the transformation of society. Traditional arts and crafts are largely faced with the impact of the industrialized production era. The craftsmen spirit that emphasizes the perfection in creation is obviously in a weak position facing the mass production and the high-efficiency industrial production. Therefore, traditional arts and crafts must be given its inherent artistic and unique

*2014, China National Social Science Fund, project number: 2014CG134, phased results

2015, China Postdoctoral Science Foundation, No. 2015M570465, Phased Results

2015, high-level "211" engineering university construction project, Fuzhou University art theory subject support plan, special results. quality that different from industrial production. Jadeite is the king of jade, because of its expensive material and complex property, it is difficult to carve. The jadeite carving master is like a dancer with a shackle. In addition to material, it is also deeply influenced by Chinese traditional culture. The theme, shape and pattern are symbols of traditional meaning. The folk craft is conservative, which reflects the traditional folk craft attributes, and this is exactly the inherent characteristic of the folk craft. The characteristic of the academic school is to accept the idea of modern art education, pays attention to the western artistic logic and expresses more epochal spirit and contemporary ideology, so its expressive meaning is more intuitive and strong. As far as the arts and crafts itself is concerned, the characteristics of jade are not only divorced from the practicality essence of the process and aesthetics, but also from the fundamental attributes of aesthetics, and become a symbol of social conception under the material natural beauty and craft beauty as well as the intermediary and medium of the moral relationship between the person in reality and the gentleman in theory. It creates the social function and scope of general art ${ }^{1}$. After the jade transcends the value judgment of the general arts and crafts, it is obviously necessary to explore the art of jadeite carving. In this article, the author combines his long-term observation, understanding and industrial investigation of the jadeite carving art process to illustrate the contradiction between the development of jadeite carving art and its internal law.

Jadeite is named for the color of its material, and its material attributes also determine the particularity of carving technique. In the jadeite stone, there are many colors, such as green, red, purple, yellow, white, etc., which constitutes the richness of jadeite. Compared to soft jade, it is more prominent. Therefore, it is more important to pay attention to colors in jadeite carving. Most of the jadeite stones are of different textures. Because of the complex patterns and impurities, we must have a foresight in the carving process and be good at handling the shortage of materials. At the same time, according to the toughness of jadeite material, it can be hollowed out. Mr Ye Jinlong, the famous master of jadeite carving in Taiwan, is known as "the first person in Chinese jadeite hollowing out".

Li Yanzu, The Way of Decoration, China Renmin University Press, June 1993, p.450 
His works are based on the tough characteristics of jadeite materials. The jadeite is mostly hollowed out, so the jadeite loses weight but not volume, which is full of tension.

Since the ancient times, the significance of cultural functions of jade has long existed. The ancients said: As a modest gentleman, if there is no special reason, he should wear a piece of jade at any time to remind him of conforming to the behavior of a gentleman and as warm as jade, giving the cultural connotation of jade "rite" and "virtue". The jadeite carving is also the bearing of traditional culture. In terms of subjects, meaning and style, the traditional jade subjects have a great influence on modern jadeite carving. The traditional creations are mostly based on the Buddha statues, ladies, landscapes and flowers and birds, which is inextricably linked with traditional Chinese painting, and the meaning is mostly auspicious peace. The traditional Chinese ideas on society is also the same as the creation of things; it emphasizes fullness on shape and tries to avoid sharp edges and corners, this has something to do with connotation and moderation of traditional Chinese culture. In addition, the warm and lustrous characteristics of the jadeite are highlighted, making the jadeite sleek in the shape.

\section{THE FOLKLORE IMPLICATION OF THE JADEITE CARVING}

In the process of the formation and development of Chinese civilization, arts and crafts gradually get rid of natural attributes and pay attention to cultural functions, and then transform into more symbolic and artistic expressions. While for the creation of crafts, it values the performance of skills. Compared to the aesthetic evolution of art, it is slow, or even retrogressive. Since ancient times, China's traditional craftsmen have been in a low status. In the process, the status has been continuously weakened, and the social stratification of the scholar, farmer, workers and merchant has affected us. In the face of traditional arts and crafts, the works are from the hands of the craftsmen, and the evaluation of the works must be affected by their social identity and cognition, then we can know the source of the artistic expression of the works.

Jade is a kind of continuous crafts in Chinese culture and has never been broken. The exploration of jadeite should begin with the understanding of the experience and cognition of the craftsmen and then enter the spiritual world of the craftsmen to further understand the jadeite carving. As the art historian Gombrich said: Art creation is a process of maternal stylization. In this process, the artist tends to paint what he wants to paint, not what he sees. ${ }^{2}$ In the long-term investigation and study of the jade industry in Sihui City, Guangdong Province, I pay special attention to the situation of the jadeite craftsmen. In the contact with the jadeite craftsmen, I know that most of them learned from the local masters in the carving industry. Their educational level is low. They have a certain ability to imitate but lack subjective consciousness.

In terms of skills, most folk craftsmen inherit the skills of their masters, and after long-term rigorous training, they have their own experience and skills. This experience shows mostly

\footnotetext{
Gombrich, Art and Optical Illusion, Zhejiang Photography Press, Nov.1987. p.101
}

folk beliefs or imitation of the aristocratic artifacts and reflects the folk customs. In the long-term slow development of the concept system, it forms the creed of folk craftsmen, so it is difficult to let them get out of the traditional sense of creation. It is from this experience that craftsmen acquire the understanding of carving, the habit of carving and expressing traditional aesthetics, and then promote the expression of folk custom. After long-term practice, they master superb carving skills and most of them can excel or master a certain type of subject carving, so as to repeatedly sculpt the same subject in order to make a living, but failed to break through the original system framework because of the lack of subjective change ideal.

In terms of concept, what is lacking is a deeper understanding of traditional culture. The expression of traditional culture lacks internal ideology. It is more about repetition and imitation of subjects and shapes, and secular expression of expectations for wealth, career and health. Such as the carving of a large number of "cabbage" for "much wealth", is just a symbol of wealth desire. Second, the traditional folk craftsmen value materials and skills, lack of awareness of modern art concepts and aesthetic vision of contemporary art. Under the impact of the aesthetic system of modern art, it seems that there is a lack of modernity related to the times.

In terms of jadeite market, the characteristics of the craftsmen's creation are also intuitively reflecting the aesthetic connotation of the public. The acceptance of the public also reflects the creation concept of the craftsmen. The folklore implication of the craftsman's creation is exactly the appreciation and taste of most people, but the jadeite carving is like the evolution of art, to some extent, the creator should go ahead of the audience's "awakening."

\section{The TIME Language IN THE EXPRESSION OF JADEITE CARVINGS OF THE ACADEMIC SCHOOL}

The evolution of arts and crafts is accompanied by the development of modern art and design. The Western pioneering practice and theoretical research in art and design have had a tremendous impact on the development of Chinese arts and crafts. At the beginning of the development of design education in China, the combination of traditional arts and crafts and Western design theory developed modern design; the development of some special arts and crafts quickly sought evolution in the direction of artistic attributes. The jadeite carving is also faced with this context. In the process of investigation, the jadeite carving also found that talents who have been educated in art colleges have gradually joined the jadeite-carved industry, facing the specialty of jadeite materials and impacting by the educational influence of art colleges on art creation at the same time. By the way, the concept of art and design creation will be brought into the jadeite carving, and the jadeite carving creation of academic school is born in such a time context.

In recent years, many art schools in China have also carried out the jadeite carving major, the exhibition and evaluation of jadeite carving gradually attracted attention of academic school. For example, in the "Zhuo Yue Cup" jadeite carving 
competition held in Guangdong Province, many works from art colleges have won the best creative awards, providing space for the recognition of jadeite carving innovation; in November 2017, "Jade · See the future - the Invitational Exhibition Jadeite carving of China Contemporary College was held at the Suzhou Arts and Crafts Institute, which was led by the university and launched an exhibition and academic discussion on the modern jadeite carving. It highlights the role of college education in actively guiding and exploring the development of traditional jadeite carving. In the practice of the development of jade, the vision of the school's works that different from the traditional ones is mainly demonstrated in the expression of its works.

In terms of materials selection, "Kaogong Ji" says: Heaven emphasizes that everything needs to be designed from the system of nature and the times. Earth emphasizes the objective conditions of nature. Beauty of materials and skills of technology emphasize subjective factors. Only things with the combination of the four factors can be called good things. As for the fact of the material beauty, the concept of the academic school is different from the traditional one. There is no definition between good materials and bad materials. It is just that people have different perspectives on the materials and give different views on the material and price positioning. In fact, different materials are suitable for different use. In material selection, works of the academic school are good at finding the characteristic attributes of the materials, and making use of them. Jadeite is a non-renewable resource. The price of materials is soaring. In the context of increasingly tight materials, it not only weakens the importance of materials in the works, but also encourages more possibilities for mining materials, rather than focusing on the quality of the materials to judge the value of the works.

In terms of theme and style, it is creative. It is not limited in the traditional imagery or too clear and direct. There are elements that borrow from traditional imagery to innovate, and there are realistic expressions of real themes and unrealistic refinements. Drawing on the modern sculpture or methods of other arts, the works tends to be abstract, including the exaggerated deformation, the emphasis on the agility of the lines, and even the deconstruction and reconstruction of the art design techniques to incorporate the consciousness of unnatural reproduction into the work design and the pluralistic sense of form responds to the aesthetic taste of the present era.

In terms of the ideological expression of the works, the creators highlight subjective emotions with closely observation in the real society so the works have obvious intentions. Their performance is direct, and they are better at creating the artistic conception of the works. It seems to reveal the non-functional considerations, but in fact guide the viewers to interpret the creative and conceptual expression of the creator. They emphasize the significance of design in creation process, dilute the attention on exquisite skills, delicate qualities in the past in the works, and transfer to the interpretation of the expressive thinking of the works. Of course, some traditional carving techniques have been abandoned, and the craft attributes of traditional carvings have been weakened to a certain extent, but the expression of artistic level and ideological level has been emphasized. The creative style of the academic school is constantly trying to innovate, using modern art aesthetic concepts and creative techniques to maintain avant-garde spirit and open up new possibilities for the development of traditional crafts.

\section{THE TIME INTEGRATION OF FOLKLORE IMPLICATION AND EXPRESSION OF JADEITE CARVING}

In the modern high-speed development, art and crafts lag behind the development of art and design. However, the lag does not mean backwardness. The development of arts and crafts is more deeply bound by tradition, and it is the recognition and inheritance of tradition that makes it to be continued. This also determines the nature of the arts and crafts, we needn't to be too aggressive to change in the development, we should adapt to its own laws, retain the tradition and slowly develop because excessive change can also destroy the traditional craft. In terms of jadeite carving, the difficulty in distinguishing jade stone from the material and the high price of the market are undoubtedly a great obstacle to innovation. It is so difficult to get raw materials that most people dare not easily try to over-innovate and create the works accepted by the public. Some folk craftsmen return to traditional practice to make jade by caring, they work slowly, and adhere to the traditional creation with the spirit of craftsman. It is the people's respect to tradition that continues the beauty of tradition and lets the splendid civilization spread to today.

However, the folklore implication will eventually change slowly with the popularity of the public, and the formation of the popular culture process will gradually change into a new aesthetic trend and evolve into a new folklore atmosphere. The debate on elegance and folklore is a hot topic often discussed in the historical development of Chinese traditional art. Just as Shi Shouqian's judgment on traditional Chinese literati paintings, he points out that literati paintings have an eternal avant-garde spirit, literati paintings repeatedly reflect ultimate essence of art while facing a strong enemy. On the one hand, it is based on the "anti-custom" tendency of the basic character of the literati; on the other hand, it shows the existence of transmission tradition of avant-garde spirit in creation. ${ }^{3}$ The evolution of an era needs an avant-garde spirit that requires creation and courage to change. The characteristics of jadeite carvings of academic school should also be printed with this historical development law. With modern art as the creative concept, combined with the traditional carving techniques to break through, this force can bring vitality to the creation of popular culture. Of course, in this process, we must master the attributes of jadeite materials, give full play to their crafts characteristics, and at the same time abandon the superficial and folklore expressions of modern art concepts. The creators themselves must constantly enrich their cultural connotations, do not be constrained by the appearance. It is necessary to deepen the aesthetic implication and charm of traditional culture in the spirit, take it as the core of creation to enhance the inner cultural taste of jadeite and to express the aesthetic taste and connotation of jadeite. At the same time, the national

Shi Shouqian, From style to painting inspiration: Reflection on the History of Chinese Art, Beijing: Life · Reading · Xinzhi Sanlian Bookstore, Aug. 2015, p64. 
intangible cultural heritage inheritance training program has been launched in various provinces and universities across the country. It is precisely the need to upgrade traditional arts and crafts, the inheritance of folk crafts techniques and the combination of educational concepts of colleges and universities that inject new cultural vitality into traditional arts and crafts.

\section{CONCLUSION}

Today, with the diversified development of the network, Chinese traditional arts and crafts must be integrated into the diversified ecological environment. In the space of jadeite carving art, the folklore implication of folk crafts and the expression embodied in the academic school together shape the charm and aesthetic height of jadeite art, just as Wang Guowei mentioned in the opening paragraph of "Human Words": There are subjective creations and objective works, which is the boundary between ideal and the realism. However, it is quite difficult to distinguish because the creations of great masters must be natural and the works is also closed to the ideal. ${ }^{4}$ Regardless of subjective creations and objective works, the most touched is that the creators will go deep into it and they will end up with the same goal. Therefore, the perfect integration of folk crafts and academic school culture in the current era is the main trend of the development and innovation of the arts and crafts, and the craft spirits can also be sublimated in the field of cultural creativity.

\section{REFERENCES}

[1] Li Yanzu, The Way of Decoration, China Renmin University Press, 1993. (in Chinese)

[2] Gombrich, Art and Optical Illusion, Zhejiang Photography Press, 1987. (in Chinese)

[3] Shi Shouqian, From style to painting inspiration: Reflection on the History of Chinese Art, Beijing: Life · Reading · Xinzhi Sanlian Bookstore, 2015. (in Chinese)

[4] written by Wang Guowei, noted by Xu Diaofu, Human words, Beijing: Zhonghua Book Company, 2012. (in Chinese)

${ }^{4}$ Written by Wang Guowei, noted by Xu Diaofu, Human Words, Beijing: Zhonghua Book Company, Jul. 2012, p.3 